\title{
Preoperative Cardiac Evaluation and Interventions Before Aortic Surgery: Are They Justified?
}

\author{
HAO BUI, M.D., and CHRISTIAN DE VIRGILIO, M.D.
}

\begin{abstract}
The role of cardiac risk assessment and preoperative cardiac intervention prior to elective vascular surgery remains controversial. In high cardiac risk patients (severe or unstable angina, recent myocardial infarction, decompensated congestive heart failure $[\mathrm{CHF}]$ ), the risk of an adverse cardiac event is so great that most would agree that these patients should undergo a preoperative cardiac work-up. In most instances strong consideration in these patients should be given to proceeding directly to coronary arteriography. In patients with low cardiac risk (those with no active cardiac symptoms, and no Eagle risk factors [angina, age $>70$ years, history of CHF, Q-wave on EKG, diabetes, ventricular ectopy requiring medication]), the adverse cardiac event rate is so low that one can proceed safely to vascular surgery without any additional cardiac testing. The moderate risk group (patients with one or more Eagle risk factors but without severe or recent cardiac symptoms) may potentially benefit from aggressive cardiac intervention. However, the pendulum appears to be swinging toward less preoperative cardiac evaluation in this group as well. Factors that favor a less aggressive approach even in these moderate risk patients include the lower cardiac morbidity and mortality following aortic surgery observed over the last decade, the lack of a good noninvasive cardiac test that is reproducibly predictive of adverse cardiac events, and the absence of data that demonstrate that subjecting a patient to three invasive procedures (coronary arteriography, coronary revascularization, and peripheral vascular operation) is less morbid than proceeding directly to peripheral vascular surgery.
\end{abstract}

Keywords Coronary artery disease, abdominal aortic aneurysm, coronary artery bypass grafting

H.B., Resident, Department of Surgery, Harbor-UCLA Medical Center; C.d.V., Associate Professor of Surgery, UCLA School of Medicine, Harbor-UCLA Medical Center, Division of Vascular Surgery, Torrance, CA.

Copyright (C) 2000 by Thieme Medical Publishers, Inc., 333 Seventh Avenue, New York, NY 10001, USA. Tel. +l(212) 584-4662. 0894-8046,p; 2000,12,2,25,42,ftx,en;pvs00060 
Adverse cardiac events are a leading source of postoperative morbidity and mortality immediately following aortic reconstruction as well as the primary cause of mortality on long-term follow-up. ${ }^{1-3}$ This is due to the high prevalence of coronary artery disease (CAD) in these patients coupled with the complexity and long duration of the operation. To reduce the incidence of adverse cardiac events following aortic reconstruction, numerous researchers have attempted to identify patients with severe CAD by either noninvasive or invasive means and then surgically correct the CAD prior to the peripheral vascular operation. There are no prospective randomized studies to date that have attempted to answer whether preoperative myocardial revascularization is efficacious, although a new trial is underway. Recent data suggest that aggressive cardiac work-up may not be necessary in most patients prior to aortic reconstruction. Whether this is a result of improved patient selection, refinement of perioperative medical management, or improved anesthetic delivery is a matter of conjecture. In this article, we review the role of preoperative cardiac evaluation and intervention before aortic reconstruction.

\section{PREVALENCE OF CAD}

In a series of 1000 consecutive patients undergoing coronary angiography prior to peripheral vascular surgery, Hertzer and colleagues identified severe surgically correctable CAD in $25 \% .^{3}$ Of the 263 patients scheduled for elective abdominal aortic aneurysm (AAA) repair, $31 \%$ were found to have severe correctable $\mathrm{CAD}$. Of the AAA patients suspected of having surgical CAD by clinical criteria, $44 \%$ were documented to have CAD on angiography. Of those without previous indication of $\mathrm{CAD}, 18 \%$ were found to have surgical CAD. ${ }^{3}$

\section{CLINICAL MARKERS FOR INCREASED CARDIAC RISK}

Goldman and colleagues proposed a risk stratification index that assigned a point value to each of the nine clinical risk factors (myocardial infarction within 6 months, age $>70$, S3 gallop or jugular venous distention, important aortic valve stenosis, rhythm other than sinus, more than five premature ventricular contractions per minute, poor general medical status, intraperitoneal, intrathoracic or aortic operation, and emergency operation). ${ }^{4}$ Patients were divided into four risk classes based on the point total. Although the index was subsequently validated, it was cumbersome to use, it did not include a history of congestive heart failure ( $\mathrm{CHF}$ ) or angina, and in the intermediate risk group had a low sensitivity for identifying patients at high risk for adverse events. Furthermore, the data set also included very few patients undergoing vascular surgery. In patients undergoing AAA repair, McEnroe and associates found that the Goldman index failed to detect many patients who subsequently developed an adverse cardiac event. ${ }^{5}$ 
Eagle et al. subsequently proposed and validated a simpler index geared specifically toward patients undergoing vascular surgery. ${ }^{6}$ In a study of 200 patients, they found 5 clinical factors that identified patients at greatest risk of cardiac events during vascular surgery (Table 1). They later added history of $\mathrm{CHF}$ as a sixth criterion. Eagle et al. found that patients with none of these clinical markers had only $3.1 \%$ risk of having an adverse postoperative cardiac event. Those with one or two criteria had a $15.5 \%$ cardiac event rate, and those with three or more of these markers had a $50 \%$ cardiac event rate. ${ }^{6}$

Others have argued that clinical assessment alone fails to detect significant CAD in patients unable to exercise and fails to identify those at risk for adverse postoperative cardiac events. Using criteria similar to those of Eagle et al. (previous MI, angina, CHF, MI on resting ECG, previous coronary artery bypass grafting $[\mathrm{CABG}])$, Cutler and Leppo concluded that these markers had no predictive value for detecting severe, surgical CAD. ${ }^{7}$ Lette and colleagues compared predictive values of 18 clinical parameters and 7 clinical scoring systems (including the Dripps-American Surgical Association score, the Goldman Cardiac Risk Index score, the Detsky Modified Cardiac Risk Index score, and the Eagle criteria) in 66 consecutive patients referred for dipyridamole-thallium imaging before major general or vascular surgery. They also found that the clinical markers had no predictive value. ${ }^{8}$

In our two prior studies, we found that none of the individual Eagle criteria were predictive of adverse cardiac events in patients undergoing major elective vascular surgery. ${ }^{9,10}$ In one of these studies, conducted at Harbor-UCLA Medical Center, the predominant Eagle risk factor was diabetes $(50 \%)$ and the primary operative procedure was infrainguinal revascularization. The subsequent study was performed at the West Los Angeles Veterans Affairs Medical Center, where diabetes $(33 \%)$, age $>70$ years $(32 \%)$, and Q-wave on EKG $(31 \%)$ were equally prevalent, and infrainguinal reconstruction was again the most common procedure. Although none of the individual Eagle criteria were predictive of an adverse event, the cardiac event rate was $0 \%$ in both studies for patients who had no Eagle criteria. Patients with one or more Eagle criteria had a statistically significant increase in adverse cardiac events $(7 \%, p<0.05) .9,10$

Table 1 Eagle Criteria for Increased Cardiac Risk

Age $>70$ years

Angina

Diabetes

Prior myocardial infarction

By history

By ECG (Q-wave)

Congestive heart failure 
In a more recent study we focused specifically on clinical risk factors in patients undergoing both open and endovascular AAA repair. On multivariate analysis, Q-wave on preoperative ECG and a history of CHF were the only Eagle criteria that were predictive of an adverse postoperative cardiac event. 11 The cardiac event rate was $20 \%$ for patients with two or more Eagle criteria versus $0 \%$ for those with one or no criterion $(p<0.0001){ }^{11}$

Although some of the aforementioned studies are somewhat conflicting, most reports support the notion that patients with no Eagle risk factors have a very low cardiac risk. Patients with one or two risk factors are at intermediate risk, whereas patients with three or more risk factors are at significantly increased risk of an adverse cardiac event.

\section{NONINVASIVE PREOPERATIVE CARDIAC EVALUATION}

\section{Exercise Electrocardiography}

Exercise electrocardiography is common tool for diagnosing significant $\mathrm{CAD}$. The test provides an estimate of functional capacity, hemodynamic response to exercise, potential for catecholamine-induced cardiac arrhythmias, and exercise myocardial ischemia threshold. ${ }^{12}$ It is best used for patients at intermediate risk for CAD. Gianrossi et al. performed a meta-analysis of 147 consecutive reports in 24,074 patients who underwent both coronary angiography and exercise testing. ${ }^{12}$ The mean sensitivity of exercise electrocardiography for multivessel CAD was $81 \%$ (range $40-100 \%$ ) with a mean specificity of $66 \%$ (range 17-100). However, the sensitivity of exercise ECG is reduced in patients who cannot reach maximum levels of exercise and in those with extensive Q-wave anterior MI on rest ECG. ${ }^{12}$ An important limitation of exercise electrocardiography in vascular patients is that 30 to $50 \%$ of patients referred to a cardiologist are unable to reach maximum levels of exercise. ${ }^{12}$

Other investigators have suggested that low exercise capacity itself is an indicator of cardiac risk. Cutler and Wheeler studied 130 patients who underwent exercise electrocardiography before vascular surgery. ${ }^{13}$ Of the patients who were able to achieve greater than $75 \%$ of predicted maximum heart rate, none suffered a postoperative cardiac complication. Patients who had inducible ischemia at low workloads ( $<75 \%$ of predicted maximum heart rate) were found to have the greatest risk of cardiac complications (38\% cardiac event rate). Thus, low exercise tolerance does not necessarily preclude use of this test, as some valuable information can still be obtained. ${ }^{13}$

\section{Left Ventricular Ejection Fraction}

Pasternack el al. suggested that a low left ventricular ejection fraction (LVEF), as measured by radionuclide angiography, is a useful predictor of 
postoperative MI in patients undergoing aortic aneurysm resection. ${ }^{14}$ More recently, McCann and Wolfe compared the cardiac event rates in patients undergoing AAA repair who had ejection fractions above and below 35\%. They found no statistical difference in operative mortality or cumulative lifetable survival rates between patients with normal and low LVEF. ${ }^{15}$ Because LVEF is a measurement of pumping capacity of the ventricle at rest, it gives little information regarding myocardial perfusion under conditions of stress.

\section{Dobutamine Stress Echocardiography}

Dobutamine stress echocardiography $(\mathrm{ECHO})$ has been advocated as a preoperative pharmacological stress test. Proponents of this test suggest obtaining coronary angiography in a patient who develops wall motion abnormalities with stress. ${ }^{16-19}$ In a study of 98 consecutive patients undergoing aortic and lower extremity revascularization, Davila-Roman et al. noted a $20 \%$ event rate in patients with a positive dobutamine test and a $0 \%$ event rate with a negative test. ${ }^{16}$ Langan and colleagues studied the predictive value of dobutamine stress echocardiography in 81 patients who underwent infrarenal aortic surgery. ${ }^{17}$ Of the 56 patients who had a normal study or resting wall motion abnormalities alone, none had a postoperative cardiac complication. Of the 25 patients with dobutamine-induced ischemia, 4 underwent CABG. Of note, two of these four patients $(50 \%)$ died after $\mathrm{CABG}$, one from a stroke and one from a ruptured aortic aneurysm. Five patients had surgery deferred. Sixteen patients with an abnormal stress ECHO underwent surgery without myocardial revascularization either because the surgery was felt to be urgent or because the stress ECHO indicated single vessel disease. Of these 16, 3 (19\%) suffered a postoperative MI. ${ }^{17}$ Lalka and associates reported a $29 \%$ cardiac event rate following aortic surgery in patients with an abnormal dobutamine study versus a $4.6 \%$ event rate with a normal study. ${ }^{18}$ They noted that a history of MI and the presence of two or more clinical risk factors (age $>70$, prior MI, CHF, cardiac symptoms) were statistically associated with a higher likelihood of a cardiac event. ${ }^{18}$

All of the above studies designs had one or more of the following limitations. Either the clinicians were not blinded to the dobutamine ECHO results and thus management was altered, the patients were not consecutive patients undergoing vascular surgery but rather selective patients referred for dobutamine testing, the data were gathered retrospectively, or patients were not stratified by Eagle risk factors. Eichelberger and colleagues studied 75 consecutive patients who had dobutamine stress echocardiography prior to major vascular surgery. ${ }^{19}$ Although the results of the two-dimensional echocardiogram were provided, the dobutamine stress portion of the exam was blinded. Sixteen patients (21\%) had significant adverse effects from the dobutamine infusion including hypotension (11\%) and severe hypertension ( $>240$ $\mathrm{mm}$ systolic, $4 \%)$. The perioperative ischemic cardiac event rate was $7 \%$. All 
five patients with cardiac events had positive dobutamine stress tests (sensitivity $100 \%$ ). The negative predictive value was also $100 \%$. However, 22 patients with a positive stress test did not have an event. Thus the positive predictive value was only 19\%. ${ }^{19}$ Thus it appears that dobutamine stress echocardiography may be most useful when negative.

\section{Dipyridamole Thallium/Sestamibi Scintigraphy Imaging}

Dipyridamole thallium scintigraphy (DTHAL) has been shown to have a high degree of sensitivity and specificity for the detection of hemodynamically significant $\mathrm{CAD}$ when compared with angiography in human studies. However, controversy exists as to whether an abnormal DTHAL is useful in predicting which vascular patients are at increased risk for perioperative adverse cardiac events. Numerous studies have investigated the value of DTHAL and dipyridamole-sestamibi (DMIBI) scintigraphy as preoperative cardiac screens for patients undergoing vascular surgery (Table 2). The finding of redistribution on DTHAL has been demonstrated in various reports to correlate with a significant increased risk of an adverse perioperative cardiac event. $6,7,21,20-22$ In a retrospective review of 254 vascular patients referred to a nuclear cardiology laboratory, Eagle and colleagues noted that the DTHAL results were best used when combined with the Eagle risk factors. ${ }^{6}$ In patients with one or two Eagle risk factors, they noted a $29.6 \%$ cardiac event rate with redistribution on DTHAL versus only a $3.2 \%$ event rate without redistribution. Forty-four patients had surgery canceled or postponed due to an abnormal DTHAL and were not included in the analysis. In a prospective study of 116 consecutive patients undergoing aortic surgery, Cutler and Leppo noted that all postoperative MIs and deaths occurred in the 54 patients with redistribution on DTHAL. 7 The results of the DTHAL were not blinded to the clinicians. Twenty patients underwent preoperative cardiac catheterization as a result of an abnormal DTHAL. One patient suffered a cerebrovascular accident as a result of the catheterization. Another patient died of a ruptured AAA while awaiting coronary revascularization. Six patients underwent CABG. One of these patients died 3 days later from hemorrhagic pancreatitis. ${ }^{7}$

More recently, the utility of DTHAL/DMIBI as a preoperative cardiac screening tool has come into question (Table 3).9,10,23-26 In two retrospective studies, de Virgilio and associates found that DTHAL and DMIBI redistribution were not predictive of adverse cardiac events in patients without severe cardiac symptoms (recent MI, unstable angina, decompensated CHF).9,10 The positive predictive values of DTHAL and DMIBI for adverse cardiac events were 6 and $10 \%$, respectively. In a prospective study of 457 consecutive patients undergoing abdominal aortic surgery, Baron et al. also found that DTHAL results did not accurately predict adverse cardiac outcomes. ${ }^{23}$ In their study, the best correlates of cardiac complications were definite clinical evidence of CAD and age greater than 65 years. ${ }^{23}$ Stratmann et al. noted a $3 \%$ 


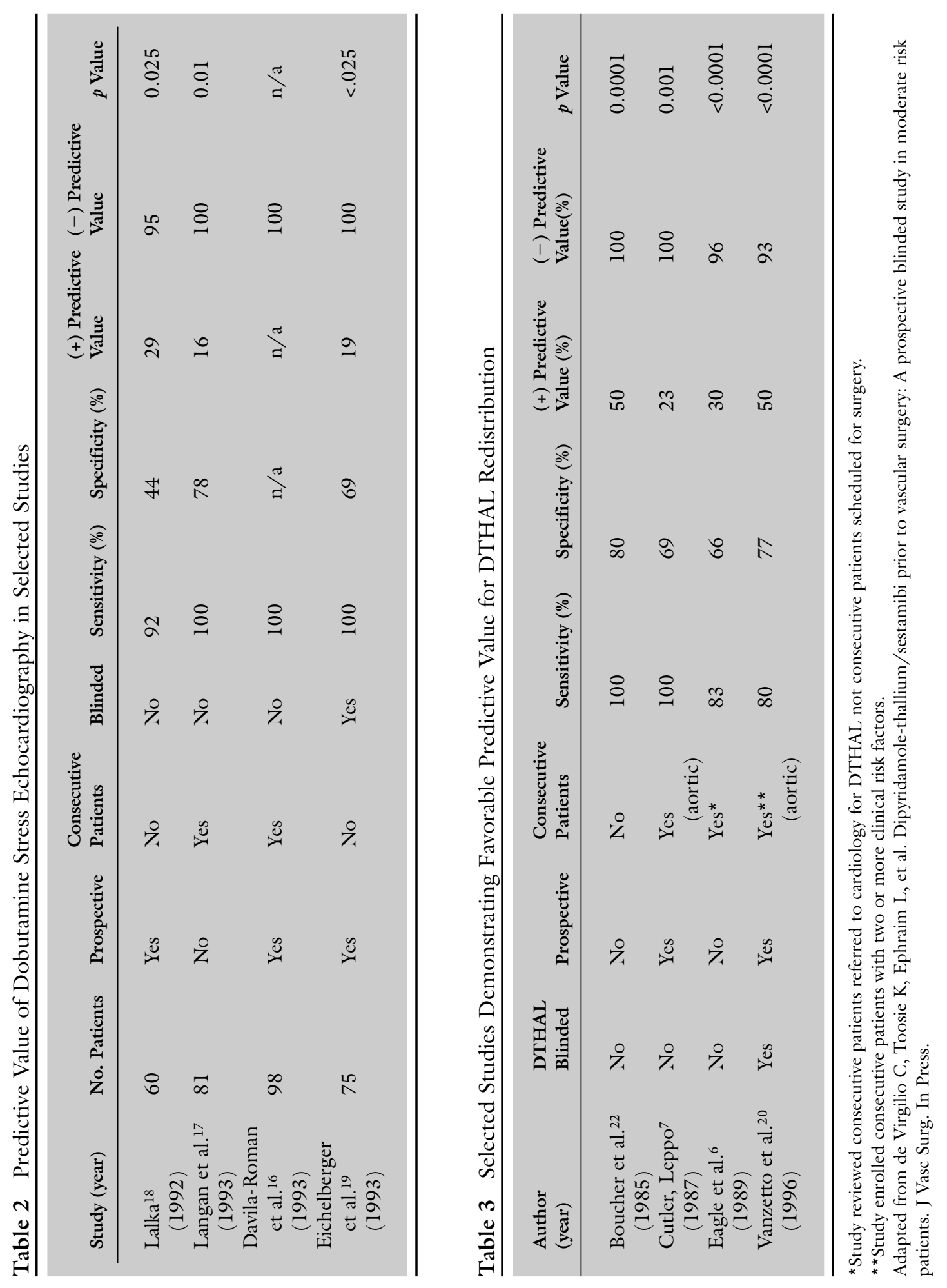

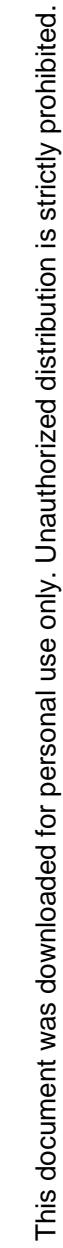


cardiac event rate in 87 patients with a normal DMIBI and a 5\% event rate in 110 patients with an abnormal DMIBI $\left(p=\right.$ NS). ${ }^{25}$ Of the 110 patients with an abnormal DMIBI, 53 had reversible ischemia, and the cardiac event rate in this subgroup of patients was $6 \%(p=N S)$. Patients with unstable angina or recent MI (within 3 months) were excluded from the study. Mangano and colleagues found no association between DTHAL redistribution and perioperative cardiac ischemia in 60 consecutive patients undergoing vascular surgery. ${ }^{24}$ Patients with recent MI (within 6 months), unstable angina, or decompensated CHF were excluded. They noted that $58 \%$ of severe perioperative cardiac ischemic episodes occurred in patients without redistribution defects. The sensitivity of DTHAL for adverse cardiac outcome was only $46 \%$, and the positive predictive value was only $27 \%$. The study was noteworthy in that, unlike the aforementioned reports, the results of the DTHAL were blinded to all clinicians. Thus, vascular surgery was neither delayed nor modified, preoperative cardiac catheterization was not obtained, and medical and anesthetic care were not changed because of the DTHAL results. ${ }^{24}$

In a more recent prospective, blinded study, de Virgilio and colleagues again found no association between a reversible defect on DTHAL/DMIBI and adverse cardiac events in 82 patients undergoing elective vascular surgery. ${ }^{27}$ Like the study of Mangano et al. vascular surgery and medical management were not modified as a result of the DTHAL/DMIBI results. To assure that patients at low risk for cardiac events were excluded, only patients with one or more Eagle risk factors were enrolled in the study. The adverse event rate was $13.8 \%$ for patients with a reversible defect and $9.8 \%$ for patients without $(p=$ 0.7). ${ }^{27}$ For patients with two or more reversible defects, the cardiac event rate was 12.5 versus $11.1 \%$ for less than two reversible defects. The sensitivity of at least two reversible defects was $11 \%$, the specificity was $90 \%$, and the positive and negative predictive values were 12.5 and $89 \%$, respectively. ${ }^{27}$

\section{CARDIAC MORTALITY FOLLOWING AORTIC RECONSTRUCTION}

The overall incidence of perioperative cardiac mortality following aortic surgery appears to be decreasing over the last 4 decades (Table 4).28-31 In 1964, DeBakey and et al. reported a 9\% 30-day mortality in 1719 patients undergoing AAA repair, with most of the deaths being due to cardiac events, although it should be noted that this study also included patients with ruptured AAA. ${ }^{28}$ In 1974, Thompson et al. noted a 5.5\% operative mortality in 108 patients undergoing AAA repair, with five of six deaths resulting from heart-related causes. ${ }^{29}$ In 1990, Johnston et al., in a prospective study of 666 patients undergoing AAA repair reported an operative mortality rate of $4.8 \%$ and cardiac related mortality of 3.3\%. ${ }^{30}$ More recently, Huber and colleagues reported a $4.9 \%$ mortality after AAA repair, with less than one third of deaths being of cardiac origin. ${ }^{31}$ Most deaths in the series were the result of multisystem organ failure (Table 5 ). 


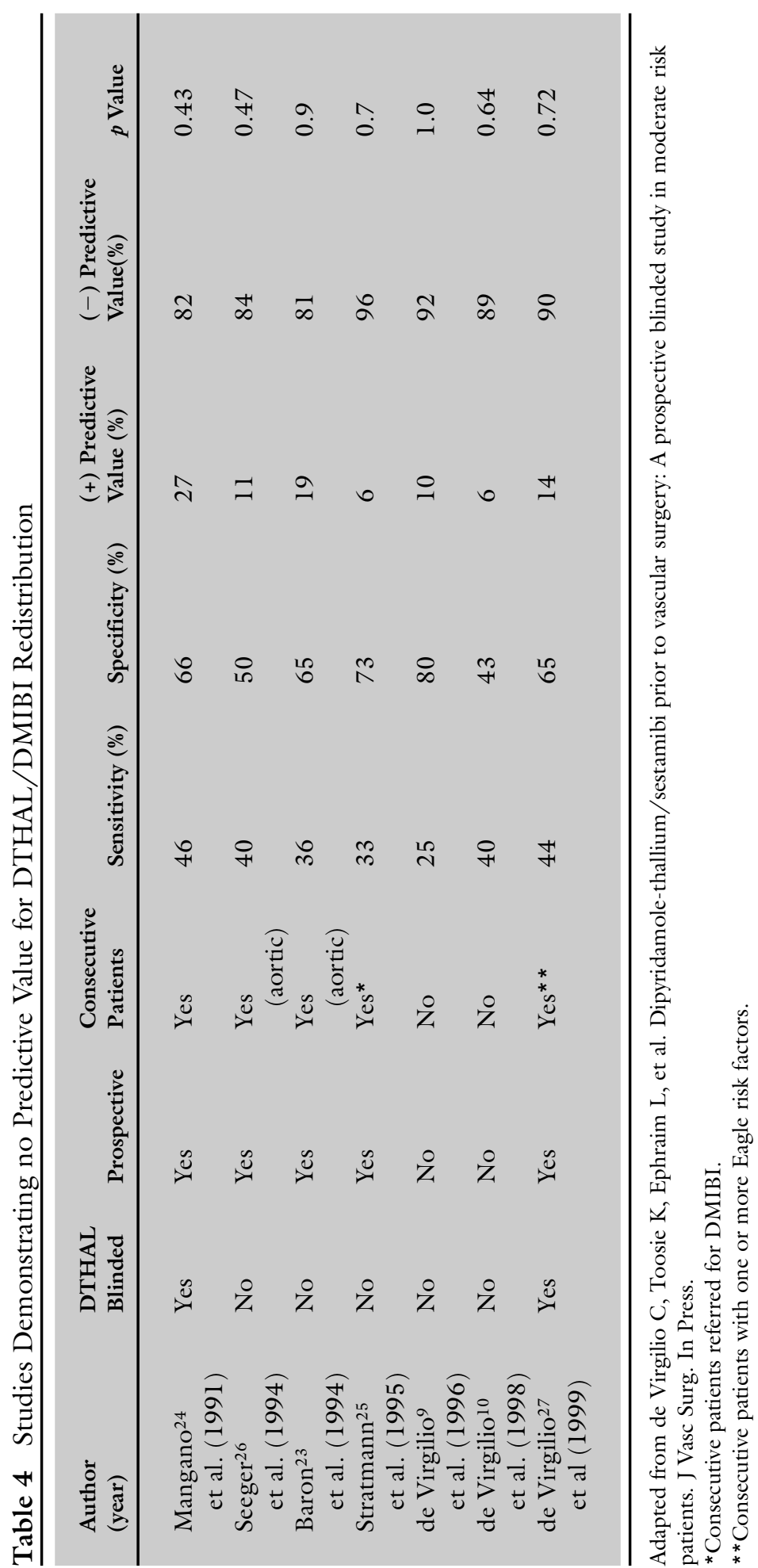


Table 5 Mortality for Abdominal Aortic Reconstructions

\begin{tabular}{llll}
\hline $\begin{array}{l}\text { Author } \\
(\text { Year })\end{array}$ & No. Patients & Mortality Rate (\%) & Cardiac Mortality Rate \\
\hline $\begin{array}{c}\text { DeBakey et al. } \\
(1964) \\
\begin{array}{c}\text { Szilagyi et al. * } \\
(1966)\end{array}\end{array}$ & 1791 & 9.0 & Majority \\
$\begin{array}{c}\text { Thompson et al. } \\
(1974)\end{array}$ & 108 & 14.7 & $7.0 \%$ \\
$\begin{array}{c}\text { Johnston et al } \\
(1990)\end{array}$ & 666 & 5.5 & $3.3 \%$ \\
$\begin{array}{c}\text { Sedwitz et al. } \\
(1990)\end{array}$ & 109 & 4.8 & $3.3 \%$ \\
$\begin{array}{c}\text { Taylor et al. } \\
(1991)\end{array}$ & $285 \#$ & 0 & $0 \%$ \\
$\begin{array}{c}\text { Cambria et al. } \\
(1992) \\
\text { Baron et al. } \\
(1994)\end{array}$ & 202 & 0 & $0 \%$ \\
$\begin{array}{c}\text { Huber et al. } \\
(1995)\end{array}$ & 457 & 2.0 & $0.5 \%$ \\
\hline
\end{tabular}

*Included elective and ruptured aneurysms.

**Included elective and symptomatic aneurysms.

\#Included all elective vascular procedures.

Adapted from Huber T, Harward T, Flynn T, et al. Operative mortality rates after elective infrarenal aortic recon-

structions. J Vasc Surg 1995;22:287-294

\section{CARDIAC MORBIDITY AND MORTALITY FOLLOWING ENDOVASCULAR AAA REPAIR}

With the advent of endovascular technology, interest has developed in determining whether endovascular AAA (EAAA) repair results in less hemodynamic stress and therefore less cardiac risk than open AAA (OAAA) repair. Baxendale and associates have demonstrated that EAAA repair causes less intraoperative hemodynamic and metabolic stress than OAAA repair. ${ }^{32}$ They noted a significant change in cardiac output, mean arterial pressure, and systemic vascular resistance with aortic crossclamping, and lower limb perfusion. With EAAA, there was only a transient rise in systemic vascular resistance with femoral artery clamping. Thus one would anticipate less cardiac morbidity and mortality with this approach. ${ }^{32}$ However, at our own institution, the cardiac event rates for OAAA and EAAA were similar ( 5 vs $6 \%$, respectively), as was the operative mortality ( 5 vs $4 \%$ ). ${ }^{11}$ Of note is that the majority of EAAA repairs were performed under general anesthesia. Henretta and colleagues recently reported EAAA repair in 47 patients under local anesthesia with intravenous 
sedation with no cardiopulmonary morbidity or mortality. ${ }^{33}$ May et al. reported 8 cardiac complications (7\%) in 108 patients who underwent attempted EAAA repair, with a $2.7 \%$ cardiac mortality, ${ }^{34}$ whereas Moore and colleagues noted one MI $(2 \%)$ and no cardiac deaths in 46 EAAA repairs. ${ }^{35}$

\section{RISKS OF CORONARY REVASCULARIZATION}

In determining whether preoperative coronary revascularization is justified prior to aortic surgery, it is important to be aware of the risks of intervention. Coronary arteriography carries a $0.15 \%$ risk of MI and a $0.3 \%$ risk of mortality. ${ }^{36}$ Percutaneous transluminal coronary angioplasty has a $6 \%$ risk of MI and a $1.8 \%$ risk of mortality. ${ }^{36}$ Patients with peripheral vascular disease, and those with diabetes in particular, have an increased mortality following CABG than those without peripheral vascular disease. Hertzer et al. reported an operative mortality rate of $5 \%$ for $\mathrm{CABG}$ in patients with peripheral vascular disease compared with a $1.2 \%$ mortality for those without. ${ }^{3}$ In a recent study from the Mayo Clinic, the mortality rate of CABG for patients 80 years and older increased from $4 \%$ without peripheral vascular disease to $16 \%$ when peripheral vascular disease was present. ${ }^{37}$

\section{DOES PREOPERATIVE CORONARY REVASCULARIZATION REDUCE THE PERIOPERATIVE CARDIAC MORBIDITY AND MORTALITY FOR SUBSEQUENT NONCARDIAC SURGERY?}

Several studies suggest that prophylactic coronary revascularization lowers the risk of subsequent adverse cardiac events during vascular surgery. In a series of 1000 consecutive patients who underwent coronary angiography prior to elective vascular surgery at the Cleveland Clinic Foundation, 216 patients underwent CABG with an operative mortality of $5.5 \%$. Of the 130 patients who subsequently underwent vascular surgery, there was only 1 death $(0.8 \%$ mortality $){ }^{3}$ In the Coronary Artery Surgery Study, patients who underwent $\mathrm{CABG}$ before noncardiac surgery had a lower mortality $(0.9 \%)$ when compared with patients with significant $\mathrm{CAD}$ who were randomized to medical therapy before noncardiac surgery (2.4\%). ${ }^{38}$ Mahar and associates noted a $5 \%$ MI rate following noncardiac surgery in 49 patients with angiographically demonstrated CAD who did not undergo preoperative CABG compared with $0 \%$ MI rate in 99 patients with preoperative CABG who underwent 168 subsequent operations. ${ }^{39}$

Fewer data are available regarding the role of preoperative percutaneous transluminal coronary angioplasty (PTCA) prior to noncardiac surgery. Huber and colleagues studied 55 consecutive patients with significant CAD referred for preoperative PTCA prior to noncardiac surgery. ${ }^{40}$ During PTCA, one patient had abrupt closure of the coronary artery leading to hemodynamic instability and emergent CABG. Another patient had a coronary artery dissection requiring $\mathrm{CABG}$. In three others, the coronary lesions could not be tra- 
versed, requiring CABG. Thus PTCA was unsuccessful in $9 \%$. Of the 50 patients with successful PTCA, I patient had a non-Q-wave MI following PTCA. Another patient had a fatal MI following thoracoabdominal aneurysm repair despite the PTCA. Two other patients had non-Q wave MIs. The overall perioperative MI rate was $5.6 \%$, and the postoperative mortality was $1.9 \%{ }_{4} 40$ In a cohort of 2452 patients undergoing AAA repair over a 10 -year period at the Mayo Clinic, Elmore and associates noted that preoperative coronary revascularization was necessary in only 100 patients $(4.1 \%) .41$ Ninety-five of these patients had symptomatic CAD (history of MI, angina, or CHF). The perioperative MI rate in these 100 patients was $5 \%$ with no postoperative mortality versus an overall mortality was $2.9 \%$ for the entire series. The authors noted that the late cardiac event rate was significantly higher in patients undergoing PTCA (56.5\%) versus those who had undergone CABG (27\%). ${ }^{41}$

More recently, several authors have questioned the role of preoperative coronary revascularization. Using a decision model to compare treatment alternatives for patients at higher risk of perioperative cardiac complications after vascular surgery, Mason et al. concluded that proceeding directly to vascular surgery without preoperative coronary arteriography led to lower morbidity and less cost. ${ }^{36}$ Subjecting a patient to preoperative invasive cardiac evaluation would expose him to risks of at least three procedures: coronary arteriography, coronary revascularization (PTCA and/or CABG), and the vascular operation. They stated that preoperative coronary revascularization would only be beneficial if the estimated operative mortality of the vascular operation was substantially higher than $5 \%$ and if the estimated operative mortality of the CABG was in the 2 to $3 \%$ range. ${ }^{36}$ Massie and colleagues compared 70 consecutive patients who underwent coronary arteriography because of 2 or more segments of redistribution on DTHAL with 70 matched patients with similar DTHAL findings who did not undergo additional evaluation. ${ }^{42}$ They found that any possible benefit from invasive cardiac evaluation was offset by three deaths and two MIs that complicated the cardiac evaluation. There was no significant difference between the coronary angiography group and the matched control group with regards to perioperative nonfatal MI (13 vs 9\%), fatal MI (4 vs 3\%), late nonfatal MI (16 vs $19 \%)$, or late cardiac death (10 vs $13 \%) .{ }^{42}$ In a prospective study over a 1 -year period, Taylor et al. noted no fatal MIs and no operative deaths among 285 elective major vascular procedures. ${ }^{43}$ The study is noteworthy in that only patients with severe symptomatic CAD (unstable angina, uncontrolled arrhythmia, severe CHF) underwent invasive cardiac testing, and only three patients had a prophylactic CABG. The authors concluded that invasive cardiac testing should be limited to patients with severe symptomatic CAD. In a prospective study, Seeger et al. compared 146 consecutive patients undergoing aortic reconstruction, DTHAL, and selective coronary revascularization with 172 historical controls who did not undergo extensive cardiac testing. ${ }^{26}$ The authors noted no difference in cardiac mortality, serious cardiac complications, or long-term cardiac mortality between the groups, in spite of the 
fact that $41 \%$ of the DTHAL group had undergone coronary arteriography and $11.4 \%$ had undergone coronary revascularization. ${ }^{26}$ Our own institutional results mirror those of Seeger et al. ${ }^{10}$ We limited coronary revascularization to patients with severe cardiac symptoms or recent cardiac events. Of the eight patients that underwent preoperative coronary revascularization, one patient $(12.5 \%)$ suffered a massive MI following preoperative PTCA. ${ }^{10}$ The adverse cardiac event rate was not different when comparing patients who underwent DTHAL testing with selective coronary revascularization versus those who did not undergo DTHAL.

\section{COSTS OF PREOPERATIVE CARDIAC TESTING}

Bry et al. estimated the cost of cardiac testing (including costs of DTHAL, selective coronary arteriography, and selective PTCA and CABG) to be $\$ 392,000$ per life saved and $\$ 181,000$ per MI prevented. ${ }^{44}$ They further noted that the positive predictive value of DTHAL was only $19 \% .{ }^{44}$ In our own study, time from evaluation to surgery significantly increased from 12 to 18 days $(p=$ 0.0003 ) in patients undergoing DTHAL without improving outcome. ${ }^{10}$

\section{CLINICAL SIGNIFICANCE OF POSTOPERATIVE CARDIAC EVENTS}

Bry et al noted a $5.9 \%$ MI rate and a $1.3 \%$ cardiac mortality following 237 major vascular procedures. ${ }^{44}$ The authors noted that the majority of MIs were clinically insignificant. Pre- and postinfarction ECHO was available in 11 of the 14 patients who suffered an MI. Eight of these 11 patients had no change in ejection fraction. ${ }^{44}$ Yeager et al. reported that patients with a perioperative non-Q-wave or "chemical" MI had a similar long-term cardiac prognosis as controls, suggesting that such an MI may not be a significant event. ${ }^{45}$ Patients with a Q-wave MI had a higher incidence of subsequent adverse cardiac events and coronary revascularization than patients without postoperative MI, but survival rates at 1 and 4 years were similar. ${ }^{45}$

\section{AORTIC SURGERY IN THE HIGH-RISK PATIENT}

One would anticipate an unacceptably high cardiac event rate in patients with high surgical risk (i.e., uncorrectable severe cardiac disease) who undergo aortic surgery. Thus the tendency would be to deny such a patient a surgical option. However, McCann and Wolfe reported no difference in operative mortality between patients with low ejection fraction $(<35 \%, 5 \%$ mortality) and higher ejection fraction ( $>35 \%, 2 \%$ mortality). ${ }^{46}$ There was also no difference in cumulative life-table survival. In a study of 106 high-risk patients from the Mayo Clinic, Hollier and associates reported a 5.7\% mortality. 47

In high-risk patients with aortoiliac occlusive disease and limb threat, one must be aware of the cardiac risks of amputation prior to denying an attempt 
at revascularization. We reported a $16 \%$ adverse cardiac event rate and a $15 \%$ perioperative mortality following amputation in patients with two or more Eagle risk factors. ${ }^{48}$

\section{LONG-TERM BENEFITS OF CARDIAC REVASCULARIZATION}

Johnston and associates noted that the late survival rate of patients with AAA was significantly less than the age- and sex-matched normal population $(60.2$ vs $79.2 \%)$ and that heart-related causes of late death (44.4 vs $34.1 \%)$ were more frequent. ${ }^{30}$ In a study of 680 patients following AAA repair, Hertzer and colleagues found that the cumulative 5 -year survival rate $(75 \%)$ and cardiac mortality rate $(5 \%)$ after CABG were nearly identical to survival figures calculated for patients having normal coronary arteries. ${ }^{49}$ In comparison, the cumulative survival and cardiac mortality rates for a small subset of patients with severe, uncorrected CAD were 29 and 34\%, respectivly. ${ }^{49}$ However, these observations may be biased in favor of the CABG group as these patients had the most favorable coronary anatomy and were thus selected for revascularization. In contradistinction, Massie et al. found that patients who underwent extended cardiac evaluation and treatment had a longer interval before their first MI but did not demonstrate an improvement in the number of fatal and nonfatal cardiac events or in survival rate over the control group. ${ }^{42}$

\section{CONCLUSION}

In high cardiac risk patients (severe or unstable angina, recent MI, decompensated CHF), the risk of an adverse cardiac event is so great that these patients should undergo aggressive cardiac workup, which in most instances would mean proceeding directly to coronary arteriography. In patients with low cardiac risk (those with no active cardiac symptoms and no Eagle risk factors), the adverse cardiac event rate is so low that these patients can proceed safely to vascular surgery without any additional cardiac testing. Although the moderate risk group (patients with no severe or recent cardiac symptoms and with one or more Eagle risk factors) may potentially benefit from aggressive cardiac work-up, recent evidence suggests that these patients do not benefit from this approach. Factors that favor a less aggressive approach even in these moderate-risk patients include the lower cardiac morbidity and mortality following aortic surgery observed in numerous studies, the lack of a good noninvasive cardiac test that is reproducibly predictive of adverse cardiac events, and the absence of data that demonstrate that subjecting a patient to three invasive procedures (coronary arteriography, coronary revascularization, and peripheral vascular operation) is less morbid than proceeding directly to peripheral vascular surgery. A prospective randomized study on the shortand long-term benefits of coronary revascularization in patients with peripheral vascular disease is currently under way as part of a VA Cooperative Study. 


\section{REFERENCES}

1. Roger V, Ballard D, Hallett J, et al. Influence of coronary artery disease on morbidity and mortality after abdominal aortic aneurysmectomy: A population based study, 1971-1987. J Am Coll Cardiol 1989;14:1245-1252

2. Bayazit M, Gol M, Battaloglu B, et al. Routine coronary arteriography before abdominal aortic aneurysm repair. Am J Surg 1995;170:246-250

3. Hertzer N, Beven E, Young J, et al. Coronary artery disease in peripheral vascular patients: A classification of 1000 coronary aginograms and results of surgical management. Ann Surg 1984;199:223-233

4. Goldman L, Caldera D, Nussbaum S, et al. Multifactoraial index of cardiac risk in noncardiac surgical procedures. N Engl J Med 1977;297:845

5. McEnroe S, O'Donnell T, Yeager A, et al. Comparison of ejection fraction and Goldman risk factor analysis to dipyridamole-thallium 201 studies in the evaluation of cardiac morbidity after aortic aneurysm surgery. J Vasc Surg 1990;1 1:497-503

6. Eagle K, Coley C, Newell J, et al. Combining clinical and thallium data optimizes preoperative assessment of cardiac risk before major vascular surgery. Ann Intern Med 1989;100:859-866

7. Cutler B, Leppo A. Dipyridamole thallium 201 scintigraphy to detect coronary artery disease before abdominal aortic surgery. J Vasc Surg 1987;5:91-99

8. Lette J, Waters D, Burnier H, et al. Postoperative myocardial infarction and cardiac death. Ann Surg 1990;211:84-90

9. de Virgilio C, Pak S, Arnell T, et al. Cardiac assessment prior to vascular surgery: Is dipyridamole-sestamibi necessary? Ann Vasc Surg 1996;10:325-329

10. de Virgilio C, Kirby L, Lewis RJ, et al. Limited utility of dipyridamole thallium for predicting adverse cardiac events after vascular surgery. Vasc Surg 1998;32:275-279

11. de Virgilio C, Bui H, Donayre C, et al. Endovascular vs open abdominal aortic aneurysm repair: A comparison of cardiac morbidity and mortality. Arch Surg 1999:947-951

12. Gianrossi R, Detrano R, Mulvihill D, et al. Exercise induced ST depression in the diagnosis of coronary artery disease: A meta-analysis. Circulation 1989;80:87-98

13. Cutler BS, Wheeler HB. Applicability and interpretationn of electrocardiographic stress testing in patients with peripheral vascular disease. Am J Surg 1981;141:501-506

14. Pasternak P, Imparato A, Bear G, et al. The value of the radionuclide angiography as a predictor of perioperative myocardial infarction in patients undergoing abdominal aortic aneurysm resection. J Vasc Surg 1984;1:320-325

15. McCann RL, Wolfe WG. Resection of abdominal aneurysm in patients with low ejection fractions. J Vasc Surg 1989;10:240

16. Davila-Roman V, Waggoner A, Sicard G, et al. Dobutamine stress echocardiography predicts surgical outcome in patients with an aortic aneurysm and peripheral vascular disease. J Am Coll Cardiol 1993;21:957

17. Langan EM, Youkey JR, Franklin D, et al. Dobuamine stress echocardiography for cardiac risk assessment before aortic surgery. J Vasc Surg 1993;18:905

18. Lalka S, Sawada S, Dalsing M, et al. Dobutamine stress echocardiography as a predictor of cardiac events associated with aortic surgery. J Vasc Surg 1992;15:831-842

19. Eichelberger J, Schwarz K, Black E, et al. Predictive value of dobutamine echocardiography just before noncardiac vascular surgery. Am J Cardiol 1993;72:602-607

20. Vanzetto G, Machecourt, Blendea D, et al. Additive value of thallium single-photon emission computed tomography myocardial imaging for prediction of perioperative events in clinically selected high cardiac risk patients having abdominal aorta surgery. Ann J Cardiol 1996;77:143-148

21. McPhail N, Ruddy T, Calvin J, et al. A comparison of dipyridamole-thallium imaging and exercise testing in the prediction of postoperative cardiac complications in patients requiring arterial reconstruction. J Vasc Surg 1989;10:51-56 
22. Boucher C, Brewster D, Darling R, et al. Determination of cardiac risk by dipyridamolethallium imaging before peripheral vascular surgery. N Engl J Med 1985;312:389-394

23. Baron JF, Munder O, Bertrand M, et al. Dipyridamole-thallium scintigraphy and gated radionuclide angiography to assess cardiac risk before abdominal aortic surgery. $\mathrm{N}$ Engl J Med 1994:330:663-669

24. Mangano D, London M, Tubau J, et al. Dipyridamole thallium-201 scintigraphy as a preoperative screening test: A reexamination of its predictive potential. Circulation 1991; $84: 493-502$

25. Stratmann H, Younis L, Wittry M, et al. Dipyridamole technetium-99m sestamibi myocardial tomography in patients evaluated for elective vascular surgery: Prognostic value for perioperative and late cardiac events. Am Heart J 1995;131:923-929

26. Seeger J, Rosenthal G, Self S, et al. Does routine stress-thallium cardiac scanning reduce postoperative cardiac complication. Ann Surg 1994;219:654-663

27. de Virgilio C, Toosie K, Ephraim L, et al. Dipyridamole-thallium/sestamibi prior to vascular surgery: A prospective blinded study in moderate risk patients. J Vasc Surg. In press.

28. DeBakey M, Crawford E, Cooley D, et al. Aneurysm of abdominal aorta: Analysis of results of graft replacement therapy one to eleven years after operation. Ann Surg 1964; 622-639

29. Thompson J, Hollier L, Patman R, Persson A. Surgical management of abdominal aortic aneuryms: Factors influencing mortality and morbidity-A 20 year experience. Ann Surg 1974;181:654-661

30. Johnston KW and the Canadian Society for Vascular Surgery Study Group. Nonruptured abdominal aortic aneurysm: Six-year follow-up results from the multicenter prospective Canadian aneurysm study. J Vasc Surg 1990;12:163-170

31. Huber T, Harward T, Flynn T, et al. Operative mortality rates after elective infrarenal aortic reconstructions. J Vasc Surg 1995;22:287-294

32. Baxendale B, Baker D, Hutchinson A, et al. Haemodynamic and metabolic response to endovascular repair of infra-renal aortic aneurysms. Br J Anaesth 1996;77:581-585

33. Henretta J, Hodgson K, Mattos M, et al. Feasibility of endovascular repair of abdominal aortic aneurysms with local anesthesia with intravenous sedation. J Vasc Surg 1999;29: 793-798

34. May J, White G, Yu W, et al. Concurrent comparison of endoluminal versus open repair in the treatment of abdominal aortic aneurysms: Analysis of 303 patients by the life table method. J Vasc Surg 1998;27:213-221

35. Moore W, Rutherford R, for the EVT Investigators. Transfemoral endovascular repair of abdominal aortic aneurysm: Results of the North American EVT Phase I trial. J Vasc Surg 1996;23:543-553

36. Mason J, Owens D, Harris R, et al. The role of coronary angiography and coronary revascularization before noncardiac vascular surgery. JAMA 1995;273:1919-1925

37. Mullaney C, Darling G, Pluth J, et al. Early and late results after isolated coronary artery bypass surgery in 159 patients age 80 years and older. Circulation 1990;82(suppl IV):229-236

38. Foster E, Davis K, Carpener J, et al. Risk of non-cardiac operation in patients with defined coronary disease: The Coronary Artery Surgery Study (CASS) Registry experience. Ann Thorac Surg 1986;41:42

39. Mahar L, Steen P, Tinker J, et. al. Perioperative myocardial infarction in patients with coronary artery disease with and without aorta-coronary artery bypass grafts. J Thorac Cardiovasc Surg 1978;76:533-537

40. Huber K, Evans M, Bresnahan J, et al. Outcome of noncardiac operations in patients with severe coronary artery disease successfully treated preoperatively with coronary angioplasty. Mayo Clin Proc 1992;67:15-21 
41. Elmore JR, Hallet J, Gibbons R, et al. Myocardial revascularization before abdominal aortic aneurysmorrhaphy: Effect of cornonary angioplasty. Mayo Clin Proc 1993;68:637

42. Massie MT, Rohrer M, Leppo J, Cutler B. Is coronary angiography necessary for vascular surgery patients who have positive results of dipyridamole thallium scans? J Vasc Surg 1997;25:975-983

43. Taylor LM, Yeager RA, Moneta G, et al. The incidence of perioperative myocardial infarction in general vascular surgery. J Vasc Surg 1992;15:52-59

44. Bry J, Belkin M, O'Donnell T, et al. An assessment of the positive predictive value and cost-effectiveness of dipyridamole myocardial scintigraphy in patients undergoing vascular surgery. J Vasc Surg 1994;19:112-124

45. Yeager R, Moneta G, Edwards J, et al. Late survival after perioperative myocardial infarction complicating vascular surgery. J Vasc Surg 1994;20:598-606

46. McCann R, Wolfe W. Resection of abdominal aortic aneurysm in patients with low ejection fractions. J Vasc Surg 1989;10:240-244

47. Hollier L, Reigel M, Kazmier F, et al. Conventional repair of abdominal aortic aneurysm in the high-risk patient: A plea for abandonment of nonresective treatment. J Vasc Surg 1986;3:712-717

48. de Virgilio C, Toosie K, Lewis RJ, et al. Cardiac morbidity and operative mortality following major lower extremity amputation: The significance of multiple Eagle criteria. Ann Vasc Surg 1999;13:204-208

49. Hertzer N, Young J, Beven E, et al. Late results of coronary bypass in patients with infrarenal aortic aneurysms: The Cleveland Clinic Study. Ann Surg 1987;205:360-367 
It is always a pleasure to review work that confirms one's own biases. The article by Bui and de Virgilio certainly fits that description. Dr. de Virgilio and his colleagues have performed and published sentinel work in the field of cardiac risk assessment, and the review reported herein summarizes their own findings as well as provides a balanced analysis of data described by others. In short, I think this monograph is remarkably concise, complete, and fair.

Coronary artery disease (CAD) remains the principal cause of both early and late mortality after peripheral vascular reconstruction, despite improvements in anesthetic techniques and patient management. ${ }^{1-11}$ The greater cardiac risk in patients undergoing vascular operations compared with those having other noncardiac surgery is in large part related to the diffuse nature of atherosclerosis and to the masking of symptoms from CAD because of limitations in activity imposed by peripheral vascular disease (PVD). Two decades ago Hertzer and colleagues firmly established the frequent association of CAD and PVD; routine coronary angiograms in 1000 consecutive peripheral vascular patients revealed severe-correctable or severe-inoperable CAD in $36 \%$ of patients with aortic aneurysms, $28 \%$ of those with lower extremity ischemia, and $32 \%$ of those with cerebrovascular disease. ${ }^{12}$ Remarkably, only 85 (8\%) of these 1000 patients had normal coronary arteries.

Such sobering statistics have led to a myriad of strategies to identify patients at high risk for adverse cardiac outcomes. Many algorithms have been proposed combining clinical risk indices, ${ }^{13-18}$ exercise treadmill testing (ETT), ${ }^{19-21}$ ambulatory electrocardiography (Holter monitoring), ${ }^{22-25}$ radionuclide ventriculography (RNVG), 26,27 dipyridamole thallium scintigraphy (DTS), ${ }^{28-32}$ dobutamine stress echocardiography, ${ }^{33,34}$ and coronary angiography. ${ }^{35,36}$ This vast array of tests and the multiple proposals for employing them indicates the absence of a consensus on the optimal approach for risk stratification in patients with peripheral arterial disease.

Equally controversial is what to do when severe, correctable CAD is identified by preoperative tests. Advocates of coronary revascularization prior to peripheral vascular operations contend that it both enhances the safety of the vascular procedure and prolongs life expectancy in these patients. Several large retrospective studies have suggested that decreased cardiac morbidity can be achieved by prophylactic coronary artery bypass grafting (CABG). ${ }^{35-40}$ Few data are available regarding the value of prophylactic percutaneous trans-

W.C.K., Professor and Chief of Vascular Surgery, Department of Surgery, University of Colorado Health Sciences Center, Denver, CO.

Copyright (c) 2000 by Thieme Medical Publishers, Inc., 333 Seventh Avenue, New York, NY 10001, USA. Tel. +1(212) 584-4662. 0894-8046,p; 2000,12,2,43,48,ftx,en;pvs00061 
luminal angioplasty (PTCA) in this setting. ${ }^{41}$ However, prophylactic CABG and PTCA are expensive and associated with substantial morbidity and mortality, leading some to caution against their use. ${ }^{42}$

Authorities who have recommended specific strategies for prevention of cardiac morbidity after vascular surgery generally have based their opinions on specific protocols designed to address this dilemma. In practice, decisions regarding cardiac workup and subsequent intervention are rarely standardized. Instead, the management plan is arrived at by a variable combination of cardiologists, anesthesiologists, and surgeons. Occasionally, anesthesiologists refuse to administer anesthesia to patients unless they are first "cleared by cardiology," as if the imprimatur of a cardiologist confers a guarantee that adverse events will be avoided.

We have recently documented the occurrence of unfavorable outcomes in one-third of candidates for vascular surgery subjected to extensive preoperative assessment of cardiac risk over a one year period. ${ }^{43}$ Remarkably, one-fifth of the patients who were so appraised elected not to undergo the vascular procedures for which their cardiac evaluations were undertaken. Most of these individuals (seven of eight) had a potentially life-threatening vascular disorder (AAA). The reasons for refusal were multifactorial, but many patients stated something to the effect that "they had been through enough." This is not especially surprising considering the asymptomatic nature of the vascular and cardiac disease in some of these patients. Although there were no deaths directly attributable to cardiac workup, the morbidity was substantial, including limb loss, prosthetic graft infection, prolonged hospitalization, multiple additional operations, and even brain damage.

It was of interest that there was no difference in cardiac morbidity between the patients who had extensive evaluations/interventions compared with those who did not. This was not a randomized trial, so it is likely that the intervention group had more severe and/or symptomatic CAD than those who proceeded more directly to vascular surgery. Proponents of an aggressive approach would argue that intervention enhanced the safety of the vascular operation, avoided potential cardiac morbidity, and perhaps extended the life expectancy of these patients. However, whatever the degree of this protection, it came at a high price, literally and figuratively. The charges for cardiac screening tests and procedures are difficult to determine at a VA medical center, but they are certainly substantial in the private sector.

In general, the incidence of the most serious adverse cardiac outcomesMI and cardiac death-is relatively low. However, up to half of postoperative MIs are fatal. ${ }^{44,45}$ The uncommon but dangerous occurrence of postoperative MI has given rise to four major approaches to preoperative risk assessment: 1) an aggressive interventional strategy such as that evaluated by Hertzer and others in Cleveland ${ }^{36,46} ; 2$ ) a rigid protocol requiring extensive preoperative testing proposed by Bunt in Loma Linda ${ }^{45} ; 3$ ) a selective evaluation recommended by several groups in Boston ${ }^{28,30,47}$; 4) a minimalist policy champi- 
oned by Taylor and colleagues in Oregon. ${ }^{42}$ Numerous variations of these approaches have also been recommended by other authorities.

Based on our findings in the outcomes study, we are swayed by the results Taylor et al. reported using a "minimalist" approach to preoperative cardiac screening. ${ }^{42}$ In a one year period, 534 vascular procedures were performed in 491 consecutive patients. Only $5.8 \%$ of patients with severe, symptomatic CAD had studies in addition to history, physical examination, and resting ECG. Despite minimal workup, the overall MI rate was only 3.9\%; MIs occurred in only $2.8 \%$ of elective cases. Potential criticisms of this economic strategy include; 1) one-fifth of the patients had previous PTCAs or CABGs; 2 ) patients were routinely studied for only the first 72 postoperative hours; and 3 ) nearly one-third of patients did not have cardiac enzymes obtained for the full 72 hours.

It is also important to consider the substantial morbidity and mortality of CABG or PTCA in elderly patients with peripheral vascular disease, many of whom also have diabetes mellitus. In the Cleveland Clinic-clearly a respected center of excellence for cardiac revascularization-266 of the 1000 consecutive vascular patients evaluated for CAD underwent prophylactic CABG: 12 of these patients died after CABG for a mortality rate of $4.5 \% .{ }^{36}$ Cutler and Leppo screened 116 patients scheduled for peripheral vascular operations with DTSs and referred 7 (6\%) for CABG. ${ }^{29}$ One patient died after CABG (14\%) and another died awaiting CABG (14\%). No operative deaths occurred after the subsequent 106 peripheral vascular operations; thus, the two deaths that occurred (1.7\%) were directly related to the cardiac screening program. Even "less invasive" PTCA carries substantial risk in the vascular population. Kip and colleagues compared short- and long-term outcomes of PTCA in 281 diabetic and 1833 nondiabetic patients in the multicenter National Heart, Lung, and Blood Institute PTCA Registry.48 Nine-year mortality was twice as high in diabetic patients $(35.9 \%$ versus $17.9 \%$ ) with nonfatal MI rates of $29.0 \%$ versus $18.5 \%$, respectively. In the small series reported by Huber et al. from the Mayo Clinic, 50 patients were identified as high risk for cardiac morbidity before vascular surgery; despite prophylactic PTCA, the incidence of perioperative nonfatal and fatal MIs was $5.6 \%$ and $1.9 \%$, respectively. 41

Optimal protocols and management guidelines ideally should arise from randomized controlled studies. Properly designed randomized trials must be instituted to confirm the value of invasive, expensive, and potentially dangerous interventions. A Department of Veterans Affairs Cooperative Trial (Coronary Artery Revascularization Prophylaxis-CARP) to investigate this issue has recently been initiated, but results will not be forthcoming for many years. ${ }^{49}$ Until then, we recommend extended cardiac evaluation and intervention only when the patient's cardiac symptoms warrant treatment; not to enhance safety of the proposed vascular procedure, because advances in surgical and anesthetic techniques and intra- and postoperative monitoring have 
reduced the morbidity and mortality of elective vascular surgery. We feel that cardiac screening tests are most useful to avoid operations in patients with less compelling indications (e.g., smaller AAAs, asymptomatic carotid stenoses, claudication), or to alter operative strategies to favor lower risk options when possible (e.g., axillobifemoral vs. aortobifemoral bypasses). At present, we recommend a minimalist approach for the cardiac evaluation of patients with "mandatory" indications for vascular reconstruction and a selective approach to those with "relative" indications. This is particularly true in view of recent reports showing a profoundly beneficial effect of administering prophlactic beta blockers to vascular surgery patients. ${ }^{50}$

\section{REFERENCES}

1. Krupski WC, Bensard DD. Preoperative cardiac risk management. Surg Clin North Am 1995;75:647-663

2. Jamieson WRE, Janusz MT, Miyagishima RT, Gerein AN. Influence of ischemic heart disease on early and late mortality after surgery for peripheral occlusive vascular disease. Circulation 1982;66(SupplI):I-92-I-97

3. Mangano DT, Browners WS, Hollenberg M, et al. Long-term cardiac prognosis following noncardiac surgery. JAMA 1992;268:233-239

4. Krupski WC, Layug EL, Reilly LM, Rapp JH, Mangano DT, and the Study of Perioperative Ischemia Research Group. Comparison of cardiac morbidity between aortic and infrainguinal operations. J Vasc Surg 1992;15:354-365

5. Krupski WC, Layug EL, Reilly LM, Rapp JH, Mangano DT, and the Study of Perioperative Ischemia Research Group. Comparison of cardiac morbidity between aortic and infrainguinal operations: Two-year follow up. J Vasc Surg 1993;18:609-617

6. Mangano DT, Browner WS, Hollenberg M, London MJ, Tubau JF, Tateo IM, and the Study of Perioperative Ischemia Research Group. Association of perioperative myocardial ischemia with cardiac morbidity and mortality in men undergoing noncardiac surgery. $\mathrm{N}$ Engl J med 1990;323:1171-1178

7. Hertzer NR. Fatal myocardial infarction following peripheral vascular operations: A study of 951 patients followed 6 to 11 years postoperatively. Cleve Clin Q 1982;49:1-11

8. Mangano DT. Perioperative cardiac morbidity. Anesthesiology 1990;72:153-184

9. Bergan JJ, Wilson SE, Wolf G, Deupree RH, and Principal Investigators of Veterans Affairs Cooperative Study 199. Unexpected, late cardiovascular effects of surgery for peripheral artery disease. Arch Surg 1992;127:1119-1124

10. Ashton CM, Petersen NJ, Wray NP, et al. The incidence of perioperative myocardial infarction in men undergoing noncardiac surgery. Ann Intern Med 1993;118:504-510

11. Abraham SA, Coles NA, Coley CM, Strauss HW, Boucher CA, Eagle KA. Coronary risk of noncardiac surgery. Prog Cardiovasc Dis 1991;34:205-234

12. Hertzer NR, Beven EG, Young JR, et al. Coronary artery disease in peripheral vascular patients: A classification of 1000 coronary angiograms and results of surgical management. Ann Surg 1984;199:223-233

13. Abraham SA, Coles NA, Coley CM, Strauss HW, Boucher CA, Eagle KA. Coronary risk of noncardiac surgery. Prog Cardiovasc Dis 1991;34:205-234

14. Goldman L. Assessment of perioperative cardiac risk. N Engl J Med 1994;330:707-709

15. Wong T, Detsky AS. Preoperative cardiac risk assessment for patients having peripheral vascular surgery. Ann Intern Med 1992;116:743-753

16. American Society of Anesthesiologists. New classification of physical status. Anesthesiology 1963;24:111-117 
17. Shah KB, Kleinman BS, Rao TL, et al. Angina and other risk factors in patients with cardiac diseases undergoing noncardiac operations. Anes Analg 1990;70:240-247

18. Yeager RA, Weigel RM, Murphy ES, McConnell DB, Sasaki TM, Vetto RM. Application of clinically valid cardiac risk factors to aortic aneurysm surgery. Arch Surg $1986 ; 121: 278-281$

19. Cutler BS, Wheeler HB, Paraskos JA, et al. Applicability and interpretation of electrocardiographic stress testing in patients with peripheral vascular disease. Am J Surg 1981;141:501-506

20. McPhail N, Calvin JE, Shariatmadar A, Barber GG, Scobie TK. The use of preoperative exercise testing to predict cardiac complications after arterial reconstruction. J Vasc Surg $1988 ; 7: 60-68$

21. McFalls EO, Doliszny KM, Grund F, Chute E, Chester E. Angina and persistent exercise thallium defects: Independent risk factors in elective vascular surgery. J Am Coll Cardiol 1993;21:1347-1352

22. Krupski WC, Layug EL, Reilly LM, Rapp JH, Mangano DT, and the Study of Perioperative Ischemia Research Group. Comparison of cardiac morbidity between aortic and infrainguinal operations. J Vasc Surg 1992;15:354-365

23. Mangano DT, Browner WS, Hollenberg M, London MJ, Tubau JF, Tateo IM, and the Study of Perioperative Ischemia Research Group. Association of perioperative myocardial ischemia with cardiac morbidity and mortality in men undergoing noncardiac surgery. $\mathrm{N}$ Engl J Med 1990;323:1171-1178

24. Pasternack PF, Grossi EA, Baumann FG, et al. The value of silent ischemia monitoring in the prediction of perioperative myocardial infarction in patients undergoing peripheral vascular surgery. J Vasc Surg 1989;10:617-625

25. McCann RL, Clements FM. Silent myocardial ischemia in patients undergoing peripheral vascular surgery: Incidence and association with perioperative cardiac morbidity and mortality. J Vasc Surg 1989;9:583-587

26. Pasternack PF, Imparato AM, Riles TS, et al. The value of the radionuclide angiogram in the prediction of perioperative myocardial infarction in patients undergoing lower extremity revascularization procedures. Circulation 1985;72(Suppl II):II-13-II-17

27. Kazmers A, Moneta GL, Cerqueira MD, et al. The role of preoperative radionuclide ventriculography in defining outcome after revascularization of the extremity. Surg Gynecol Obstet 1990;171:481-488

28. Boucher CA, Brewster DC, Darling RC, Okada RD, Strauss HW, Pohost GM. Determination of cardiac risk by dipyridamole-thallium imaging before peripheral vascular surgery. N Engl J Med 1985;312:389-394

29. Cutler BS, Leppo JA. Dipyridamole thallium 201 scintigraphy to detect coronary artery disease before abdominal aortic surgery. J Vasc Surg 1987;5:91-100

30. Eagle KA, Coley DM, Newell JB, et al. Combining clinical and thallium data optimizes preoperative assessment of cardiac risk before major vascular surgery. Ann Intern Med $1989 ; 110: 859-866$

31. Makaroun MS, Shuman-Jackson N, Rippey A, Schreiner D, Arvan S. Cardiac risk in vascular surgery: The oral dipyridamole-thallium test. Arch Surg 1990;125:1610-1613

32. Brown KA, Rowen M. Extent of jeopardized viable myocardium determined by myocardial perfusion imaging best predicts perioperative cardiac events in patients undergoing noncardiac surgery. J Am Coll Cardiol 1993;21:325-340

33. Lalka SG, Sawada SG, Dalsing MC, et al. Dobutamine stress echocardiography of cardiac events associated with aortic surgery. J Vasc Surg 1992;15:831-842

34. Poultryman D, Foretell PM, Foster T, et al. Dobutamine stress echocardiography for assessment of perioperative cardiac risk in patients undergoing major vascular surgery. Circulation 1993;87:1506-1512 
35. Hertzer NR. Fatal myocardial infarction following peripheral vascular operations: A study of 951 patients followed 6 to 11 years postoperatively. Cleve Clin Q 1982;49:1-11

36. Hertzer NR, Beven EG, Young JR, et al. Coronary artery disease in peripheral vascular patients: A classification of 1000 coronary angiograms and results of surgical management. Ann Surg 1984;199:223-233

37. Ennix CL, Lawrie GM, Morris GC, et al. Improved results of carotid endarterectomy in patients with symptomatic coronary disease: An analysis of 1,546 consecutive carotid operations. Stroke 1979;10:122-125

38. McCollum CH, Garcia-Rinaldi R, Graham JM, DeBakey ME. Myocardial revascularization prior to subsequent major surgery in patients with coronary artery disease. Surgery 1977;81:302-304

39. Reul GJ Jr, Cooley DA, Duncan JM, et al. The effect of coronary bypass on the outcome of peripheral vascular operations in 1093 patients. J Vasc Surg 1986;3:788-798

40. Foster ED, Davis KB, Carpenter JA, Abele S, Fray D. Risk of noncardiac operation in patients with defined coronary disease: The Coronary Artery Surgery Study (CASS) registry experience. Ann Thorac Surg 1986;41:42-50

41. Huber KC, Evans MA, Bresnahan JF, Gibbons R, Holmes DJ. Outcome of noncardiac operations in patients with severe coronary artery disease successfully treated preoperatively with coronary angioplasty. Mayo Clin Proc 1992;67:15-21

42. Taylor LM, Yeager RA, Moneta GL, McConnell DB, Porter JM. The incidence of perioperative myocardial infarction in general vascular surgery. J Vasc Surg 1991;15:52-61

43. Krupski WC, Nehler MR, Whitehill TA, et al. Outcomes of cardiac evaluation before vascular surgery. Vascular Medicine 2000;5:3-9

44. Mangano DT, London MJ, Hollenberg M, et al. Perioperative myocardial ischemia in patients undergoing noncardiac surgery-I: Incidence and severity during the four-day perioperative period. J Am Coll Cardiol 1991;17:843-850

45. Bunt TJ. The role of a defined protocol for cardiac risk assessment in decreasing perioperative myocardial infarction in vascular surgery. J Vasc Surg 1992;15:626-634

46. Hertzer NR. Basic data concerning associated coronary disease in peripheral vascular patients. Ann Vasc Surg 1987;1:616-620

47. Golden MA, Whittemore AD, Donaldson MC, Mannick JA. Selective evaluation and management of coronary artery disease in patients undergoing repair of abdominal aortic aneurysms. Ann Surg 1990;212:415-423

48. Kip KEY, Faxon DP, Detre KM, et al. Coronary angioplasty in diabetic patients: The National Heart, Lung, and Blood Institute Percutaneous Tansluminal Coronary Angioplasty Registry. Circulation 1996;94:1818-1825

49. McFalls EO, Ward HB, Krupski WC, et al. Prophylactic coronary artery revascularization for elective vascular surgery: Study Design. Cont Clin Trials 1999;20:297-308

50. Poldermans D, Boersma E, Bax JJ, et al. The effect of bisoprolol on perioperative mortality and myocardial infarction in high-risk patients undergoing vascular surgery. N Engl J Med 1999;341:1789-1794 
The strong association of coronary artery disease with peripheral arterial occlusive or aneurysmal disease is well established. ${ }^{1,2}$ Recognizing a clearly increased incidence of significant perioperative cardiac events with vascular surgical procedures compared to most other noncardiac operations, many diagnostic modalities have been proposed and studied in an attempt to stratify such a patient's cardiac risk preoperatively.

Just as routine coronary angiography is not indicated prior to vascular surgery, Doctors Bui and de Virgilio argue correctly that "routine" preoperative stress testing is not necessary in all patients undergoing aorto-iliac operations. In the absence of the independent and cumulatively predictive clinical risk factors of diabetes mellitus, angina pectoris, congestive heart failure, or prior myocardial infarction, a physically active patient requires no preoperative stress test. ${ }^{3,4}$ In the presence of such clinical predictors, particularly ongoing angina pectoris, stress testing is indicated especially if the patient is sedentary or unable to be physically active. ${ }^{4}$ As Doctors Bui and de Virgilio note, pharmacologic stress testing employing either nuclear perfusion or echocardiographic imaging have reassuringly high negative predictive value (often greater $>95 \%$ ) but low positive predictive value (not uncommonly 15-25\%). The prior reports cited are generally flawed in that the results of pharmacologic stress testing altered preoperative patient management favorably impacting on perioperative outcome, hence diminishing positive predictive value of the diagnostic test itself.

In a much better study, Poldermans et al. ${ }^{5}$ reported results of 302 patients undergoing peripheral vascular surgery in whom the results of dobutamine stress echocardiography were not employed in preoperative management. In this study, neither the extent nor severity of ischemic regional wall motion abnormalities were independently predictive of perioperative ischemic cardiac events (unstable angina, nonfatal or fatal myocardial infarction). However, ischemia detected at a low heart rate, defined as $<70 \%$ age predicted maximal heart rate, had a positive predictive value of $53 \%$; $75 \%$ of all perioperative events occurred in patients with a low ischemic threshold. Excluding patients without the above-mentioned clinical risk factors, the positive predictive value of dobutamine stress echocardiography approached $60 \%$ when utilizing the low heart rate ischemic threshold with a negative predictive value of $100 \%{ }^{5}$ Realizing no diagnostic study can offer both very high sensitivity and specificity, the above findings present a stronger argument for the utility of

Assistant Professor of Medicine, Division of Cardiovascular Diseases and Internal Medicine, Mayo Clinic and Foundation, Rochester, MN.

Copyright (C) 2000 by Thieme Medical Publishers, Inc., 333 Seventh Avenue, New York, NY 10001, USA. Tel. +l(212) 584-4662. 0894-8046,p; 2000,12,2,49,52,ftx,en;pvs00062 
preoperative stress testing for the identification of potentially high-risk patients in whom coronary angiography may be warranted.

Evidence of myocardial ischemia on any type of preoperative stress testing certainly does not mandate coronary angiography anticipating coronary revascularization, particularly if ischemia is localized and occurring at a high ischemic threshold. There have been no controlled randomized trials yet published demonstrating coronary revascularization by any method to improve the perioperative cardiac outcome of vascular surgery.

There are, however, randomized studies reporting the efficacy of perioperative beta-blockade in the reduction of cardiac events complicating noncardiac surgery. 6,7 In a randomized trial employing atenolol, Mangano et al. reported no ischemic cardiac events (myocardial infarction, unstable angina, or need for coronary revascularization) in patients randomized to atenolol compared to a $12 \%$ incidence of such events in control patients from the immediate perioperative period to six months after noncardiac surgery. ${ }^{6}$ Approximately $40 \%$ of patients in each patient group in this study underwent major vascular surgery. In the very recent study by Poldermans et al., patients with evidence of myocardial ischemia on dobutamine stress testing were randomized to beta-blocker therapy with bisoprolol $(n=59)$ versus other medical therapy $(n=53)$ and underwent vascular surgery without preoperative coronary revascularization. Perioperative cardiac death or nonfatal myocardial infarction occurred in only two $(3.4 \%)$ patients treated with bisoprolol versus $18(34 \%)$ control patients. ${ }^{7}$ This represented a highly significant reduction in cardiac events with beta-blocker therapy, even in patients with ischemia clearly demonstrated on preoperative pharmacologic stress testing.

Given the advances being made in vascular surgical techniques, anesthetic methods and management, and recognition of the importance of postoperative cardiac surveillance, the mortality and morbidity rates of even the most extensive vascular surgical procedures continues to decrease. In the absence of unstable ischemic syndromes or high-risk stress test results, the cardiac risk of vascular surgery may be commensurate or even less than that of coronary revascularization. Unlike prior experience reported with coronary revascularization prior to noncardiac surgery, there are now randomized trials, ${ }^{6,7}$ albeit small, providing evidence-based rationale for perioperative beta-blocker medical therapy anticipating an acceptably low incidence of perioperative ischemic cardiac events during vascular surgery. As stated in the position paper of the American College of Cardiology/American Heart Association Task Force on Practice Guidelines, "invasive intervention is rarely necessary to lower the risk of surgery unless such intervention is indicated irrespective of the preoperative context." 4

\section{REFERENCES}

1. Hertzer NR. Basic data concerning associated coronary disease in peripheral vascular patients. Ann Vasc Surg 1987;1:616-620 
2. Roger VL, Ballard DJ, Hallett JW Jr, Osmundson PJ, Puetz PA, Gersh BJ. Influence of coronary artery disease on morbidity and mortality after abdominal aortic aneurysmectomy: a population-based study, 1971-1987. J Am Coll Cardiol 1989;14:1245-1252

3. Eagle KA, Coley CM, Newell JB, et al. Combining clinical and thallium data optimizes preoperative assessment of cardiac risk before major vascular surgery. Ann Intern Med 1989;110:859-866

4. Eagle KA, Brundage BH, Chaitman BR, et al. Guidelines for perioperative cardiovascular evaluation for noncardiac surgery: report of the American College of Cardiology/American Heart Association Task Force on Practical Guidelines (Committee on Perioperative Cardiovascular Evaluation for Noncardiac Surgery). J Am Coll Cardiol 1996;27:910-948

5. Poldermans D, Arnese M, Fioretti PM, et al. Improved cardiac risk stratification in major vascular surgery with dobutamine-atropine stress echocardiography. J Am Coll Cardiol $1995 ; 26: 648-653$

6. Mangano DT, Layug EL, Wallace A, Tateo I. Effect of atenolol on mortality and cardiovascular morbidity after noncardiac surgery. N Engl J Med 1996;335:1713-1720

7. Poldermans D, Boersma E, Bax JJ, et al. The effect of bisoprolol on perioperative mortality and myocardial infarction in high-risk patients undergoing vascular surgery. N Engl J Med 1999;341:1789-1794 
We thank Drs. Krupski and Freeman for their commentaries and recognize their expertise in the field of cardiac risk assessment. It is noteworthy that Dr. Krupski was one of the co-authors in the landmark study by Mangano et al., ${ }^{1}$ which first demonstrated that dipyridamole-thallium had poor predictive value for adverse cardiac events in patients undergoing vascular surgery. ${ }^{1}$

The role of cardiac risk assessment prior to vascular surgery remains in a state of flux. Prior to the 1970s, little attention was paid to trying to objectively determine a patient's likelihood of a perioperative cardiac event. With the realization that most postoperative morbidity and mortality was cardiac in nature, numerous cardiac risk indices were created, including those advocated by Dripps, Goldman, Detsky, and Eagle. ${ }^{2}$ This in turn helped ignite florid growth in the disciplines of interventional cardiology and radiology. Numerous new imaging modalities were developed. Fueled by this enthusiasm, routine cardiac testing was espoused by many cardiologists in the 1980s and early 1990s, not just for moderate and high risk patients undergoing aortic surgery, but for all patients undergoing major vascular surgery, as well as other major procedures.

As we enter the new millennium, enthusiasm for aggressive preoperative cardiac workup has been tempered by studies that question the predictive value of many of these imaging techniques. Enthusiasm has also been moderated by the realization that cardiac testing is a double edged sword. Cardiac testing may identify significant CAD but it adds expense and delays the definitive operation. Preoperative noninvasive tests may lead to further invasive cardiac tests and/or interventions to further delineate/correct CAD, but this in turn may cause the very same serious life threatening complications that are trying to be prevented. As pointed out by Dr. Krupski, we all can recall at least one patient who ruptured their aortic aneurysm while awaiting cardiac clearance, or suffered a massive MI while undergoing percutaneous coronary angioplasty for an asymptomatic coronary artery stenosis. While such stories may seem anecdotal, the mounting body of evidence supports the notion that routine cardiac testing should not be performed. We agree with Drs. Krupski and Freeman that cardiac testing should be reserved for high risk patients with overt, severe cardiac symptoms. The other group in whom cardiac testing should be considered is those patients with multiple Eagle risk factors. The main issue with this group is what test to obtain. Given the recent data on the poor predictive value of dipyridamole-thallium, and the limited data on dobutamine ECHO, the question is whether these moderate

Copyright (C) 2000 by Thieme Medical Publishers, Inc., 333 Seventh Avenue, New York, NY 10001, USA. Tel. +l(212) 584-4662. 0894-8046,p; 2000,12,2,53,54,ftx,en;pvs00062A 
risk should patients proceed directly to coronary angiography. Whether preoperative coronary revascularization followed by vascular surgery is less risky than proceeding directly to vascular surgery is not yet known. We eagerly await the results of the study by Dr. Krupski and colleagues (Coronary Artery Revascularization Prophylaxis study). ${ }^{3}$ Until then our bias is that the best results in moderate risk patients can be achieved by directly proceeding to surgery without cardiac workup, and instead focusing on delivering excellent anesthesia, use of superior surgical technique, and as pointed out by Dr. Freeman, the administration of perioperative beta blockade.

\section{REFERENCES}

1. Mangano D, London M, Tubau J, et al. Dipyridamole-thallium-201 scintigraphy as a preoperative screening test: A re-examination of predictive potential. Circulation 1991;84: 493-502

2. Mangano D, et al. Perioperative cardiac morbidity. Anesthesiology 1990;72:153-184

3. McFalls EO, Ward HB, Krupski WC, et al. Prophylactic coronary artery revascularization for elective vascular surgery: Study design. Cont Clin Trials 1999;20:297-308 